\title{
Kvalitetssikring ved dødsfall i sykehus
}

\author{
Sammendrag \\ Bakgrunn. En systematisk gjennom- \\ gang av dødsfallene ved Akershus \\ universitetssykehus ble iverksatt for \\ å vurdere omfanget av feil i dødsattes- \\ tene og for å bedre oppfølgingen av lov- \\ pålagte meldinger.
}

\begin{abstract}
Materiale og metode. Dødsattester og sykehistorier for de 496 pasienter som døde ved Akershus universitetssykehus fra 1. mai til 31. desember 2008 ble prospektivt gjennomgått. Tilbakemelding til lege ble gitt der det var ulogisk oppsett av dødsattesten eller manglet vesentlige kliniske funn samt ved mistanke om unaturlig død eller dødelig legemiddelbivirkning. For vurdering av kvaliteten på dødsattestene før studiestart ble 134 dødsfall fra mars måned i 2007 og i 2008 undersøkt retrospektivt.
\end{abstract}

Resultater. Ukorrekt innhold, men logisk oppsett eller ukorrekt innhold og ulogisk oppsett ble påvist i $27 \%$ av dødsattestene i de retrospektivt undersøkte dødsfallene og i $20 \%$ av dødsattestene i prosjektperioden. I løpet av prosjektperioden $ø$ kte andelen logiske oppsett fra $64 \%$ til $76 \%$ ( $p=0,047)$ og andelen korrekte oppsett fra $76 \%$ til $84 \%(p=0,029)$. Andelen unaturlige dødsfall vurdert retrospektivt og i prosjektperioden var henholdsvis $7 \%$ og $12 \%$, andelen legemiddelrelaterte dødsfall $7 \%$ og $5 \%$.

Fortolkning. Hensynet til dødsårsaksstatistikk og melderutiner tilsier at det er behov for kontinuerlig gjennomgang av dødsfall. Oppfølgingen ved sykehusene bør sentraliseres og gjøres av patolog eller annen lege med liknende kompetanse. Fortløpende tilbakemelding til kliniker vil heve kvaliteten på dødsattestene og øke bevisstheten rundt lovpålagte melderutiner.
Utdrag av data ble presentert muntlig på årsmøtet i Den norske patologforening på Lørenskog 27.3. og 28.3. 2009.

\section{G. Cecilie Alfsen}

cecilie.alfsen@medisin.uio.no

Patologisk anatomisk avdeling Laboratoriesenteret

Akershus universitetssykehus

1478 Lørenskog

og

Medisinsk fakultet

Universitetet i Oslo

\section{Lars Gustav Lyckander}

Patologisk anatomisk avdeling

Laboratoriesenteret

\section{Anne Wenche Lindboe}

Helge Svaar

Kvalitetsenheten

Akershus universitetssykehus

Når pasienter dør, har legene en unik rolle. De skal ikke bare etter beste evne angi dødsårsak og dermed kvalitetssikre diagnostikk og behandling, de skal også melde fra om bivirkninger og mulige feil ved utredning og behandling. Det er innlysende at man i disse situasjonene har behov for innsyn fra en tredje part. Ved større sykehus hadde patologene tidligere en uoffisiell, men viktig rolle som «screenere» av sykehistorien ved dødsfall. Å begjære obduksjon var del av rutinen og ble som regel gjort samtidig med utfylling av «Legeerklæring om død/unaturlig dødsfall» (dødsattest). Papirjournalen fulgte liket til patologiavdelingen, der patologene etter gjennomgang av sykehistorien vurderte hvilke tilfeller som burde undersøkes videre med obduksjon. Overgang til elektronisk pasientjournal har ført til at denne screeningrutinen er falt bort. I tillegg har krav i nye forskrifter om muntlig informasjon om obduksjon til de pårørende endret vinklingen på avgjørelsen om obduksjon fra å være et faglig begrunnet kvalitetssikringsspørsmål til et spørsmål om klinikeren har anledning til å samtale med de pårørende (1). Et stadig mindre antall dødsfall ved sykehusene underkastes derfor en vurdering av tredjepart.

Stikkprøver ved Akershus universitetssykehus vinteren 2008 viste at det var flere feil i dødsattestene, både i logikk og innhold. Det ble også funnet underrapportering av mulige unaturlige dødsfall og alvorlige legemiddelbivirkninger. Vi initierte derfor en systematisk studie av alle dødsfall ved sykehuset for å finne omfanget av denne type underrapportering. I tillegg ønsket vi å vurdere effekten av løpende tilbakemelding til klinikerne om kvaliteten på dødsattestene.

\section{Materiale og metode}

En prospektiv registrering av alle dødsfall hos innlagte i alderen to år og eldre ble gjennomført over åtte måneder, fra 1. mai til og med 31. desember 2008. Alle døde som ble anbrakt i sykehusets kjølerom ble rutinemessig registert i likprotokollen av ansvarshavende obduksjonslaborant ved patologiavdelingen. Laboranten skrev daglig ut dødsattest på alle avdøde som hadde vært innlagt. De som døde i mottakelsen eller på vei til sykehuset, ble inkludert hvis det var opprettet journal og en av sykehusets leger hadde skrevet dødsattesten. Alle dødsfall ble gjennomgått fortløpende av én av to patologer (GCA og LGL). Dødsfall i helger og på helligdager ble gjennomgått første vanlige arbeidsdag.

Dødsattesten ble først vurdert med henblikk på logisk og medisinsk korrekt oppbygging av årsakskjeden under punkt I og dens forhold til sykdommer nevnt under punkt II. Vurderingen fulgte de retningslinjer som er gitt på dødsattesten. Bedømmingen ble gjort uten kjennskap til sykehistorien. Deretter ble attesten vurdert $\mathrm{i}$ henhold til den konkrete sykehistorien, basert på opplysninger i den elektroniske pasientjournalen. Ved funn av mulige feil eller avvik fra sykehistorien ble den legen som hadde signert dødsattesten kontaktet elektronisk via journalsystemet og bedt om å komme med en fornyet vurdering i henhold til patologens kommentar. (En slik elektronisk melding er personlig til den enkelte lege og slettes uten spor etter 30 dager.) Kommentarene inneholdt både forslag til alternativt oppsett $o g$ diskusjoner rundt hvilke sykdommer som skulle inkluderes i attesten. Dødsattestene ble ikke foreslått korrigert, da intensjonen først og fremst var å fremme læring. Feil i forhold til innholdet i sykehistorien ble regi-

\section{Hovedbudskap}

- Fallende obduksjonsfrekvenser gjør nytenkning rundt kvalitetssikring ved $\mathrm{d} ø \mathrm{~d}$ nødvendig

- I en femdel av dødsattestene blir det sannsynligvis registrert feil dødsårsak

- Løpende tilbakemelding til legene øker kvaliteten på dødsattestene

- Gjennomgang av dødsattester og sykehistorier ved død bør være fast rutine og håndteres av én definert legegruppe 
strert hvis det ble antatt at dette ville påvirke tilgrunnliggende dødsårsak i dødsårsaksregisteret (2). Patologene diskuterte fortløpende alle dødsattester der det etter kontakt med utfyllende lege fortsatt var tvil om oppsettet var ulogisk eller i tråd med sykehistorien. Tilfeller der man ikke oppnådde noen sikker konklusjon, ble registrert som usikre.

Ved avdekking av mulig unaturlig dødsfall ble den lege som hadde synet liket forsøkt kontaktet muntlig. Vedkommende ble bedt om å melde dødsfallet til politiet samt å fylle ut et skjema om personskade til Helsetilsynet (IK2448). Alternativt ble dødsfallet diskutert med seksjons- eller avdelingsoverlegen ved den avdeling der pasienten døde. Ved uenighet mellom kliniker og patolog om behovet for melding ved mulig feil eller uhell i den medisinske behandling ved sykehuset skulle kvalitetsenheten, som overordnet ansvarlig for håndteringen av pasientrelaterte avvik ved sykehuset, kontaktes for endelig avgjørelse. Patologen skulle ikke selv melde dødsfall til politiet.

Ved mistanke om dødelig legemiddelbivirkning ble kliniker varslet elektronisk og bedt om å kommentere spørsmålet om melding til regionalt legemiddelinformasjonssenter (RELIS).

For å kunne vurdere eventuelle endringer i kvaliteten på dødsattestene ble også sykejournaler for mars 2007 og mars 2008 undersøkt retrospektivt.

Avvik mellom dødsattestoppsett og epikriser eller ICD-koding ble ikke registrert, verken i det prospektive eller i det retrospektive materialet.

Datafilene ble oppbevart på en separat sykehusserver for sensitivt materiale. Før statistisk håndtering i eksternt IT-system ble filene anonymisert. Prosjektet er godkjent av personvernombudet ved sykehuset.

Khikvadrattest for analyse av kvalitetsendringer i dødsattestutfyllingen ble utført i SPSS, versjon 16.0. P-verdier $<0,05$ ble ansett som statistisk signifikante.

\section{Resultater}

Totalt ble sykehistorien ved 630 dødsfall undersøkt. Fordelingen med hensyn på kjønn, alder og liggedøgn er presentert i tabell 1 . Hoveddelen av de avdøde hadde norsk etnisk tilhørighet (609 av 630). I prosjektperioden mai-desember 2008 døde det 62 pasienter i gjennomsnitt per måned. For patologene tilsvarte dette en gjennomgang av i snitt tre sykehistorier hver av ukens ordinære arbeidsdager. Arbeidsbelastningen varierte, men utgjorde ca. én time daglig. Det ble gitt tilbakemelding til legene ved 218 av dødsfallene (44\%). Gjennomsnittlig antall meldinger per lege var 1,4, det meste var sju meldinger til én lege.

Tabell 2 angir resultatene av dødsattestvurderingen ut fra logisk oppbygning og $\mathrm{i}$ forhold til sykehistorie. En tredel av attestene var ulogisk satt opp, vurdert både retro-

Tabell 1 Kliniske karakteristika

\begin{tabular}{lcc} 
Tidsperiode & Mars 2007 og mars 2008 & Mai-desember 2008 \\
\hline $\begin{array}{l}\text { Antall døde } \\
\text { Kvinner/menn }\end{array}$ & 134 & 496 \\
$\begin{array}{l}\text { Gjennomsnittsalder ved død (år) } \\
\text { Kvinner/menn }\end{array}$ & $63 / 71$ & $228 / 268$ \\
\hline $\begin{array}{l}\text { Liggetid (døgn), median } \\
\text { Kvinner/menn }\end{array}$ & $76 / 76$ & $77 / 75$ \\
& $6 / 7$ & $5 / 6$
\end{tabular}

\begin{tabular}{|c|c|c|c|c|}
\hline & Logisk ja & Logisk nei & Logisk usikker & Samlet \\
\hline Mars 2007 og mars 2008 & Antall (\%) & Antall (\%) & Antall (\%) & Antall (\%) \\
\hline Korrekt ja & $76(57)$ & $21(16)$ & 0 & 97 (72) \\
\hline Korrekt nei & $14(10)$ & $22(16)$ & 0 & $36(27)$ \\
\hline Korrekt usikker & $1(1)$ & 0 & 0 & $1(1)$ \\
\hline Samlet & $91(68)$ & $43(32)$ & 0 & $134(100)$ \\
\hline \multicolumn{5}{|l|}{ Mai-desember 2008} \\
\hline Korrekt ja & 311 (63) & $71(14)$ & $7(1)$ & 389 (78) \\
\hline Korrekt nei & $22(4)$ & $76(15)$ & 0 & $98(20)$ \\
\hline Korrekt usikker & $5(1)$ & $3(1)$ & $1(1)$ & $9(2)$ \\
\hline Samlet & $338(68)$ & $150(30)$ & $8(2)$ & $496(100)$ \\
\hline
\end{tabular}

spektivt og prospektivt. Andelen attester med ukorrekt innhold var samlet sett mindre i prosjektperioden enn i de retrospektivt undersøkte månedene (20\% versus $27 \%)$. Eksempler på ulike typer feil i oppsett og deres betydning for dødsårsaksregistreringen er gitt i tabell 3 .

En sammenlikning av dødsattestoppsettene $\mathrm{i}$ de åtte månedene i prosjektperioden viste signifikant bedring over tid (fig 1). Andelen attester med logisk oppsett økte fra $64 \%$ i studiens to første måneder til $76 \%$ i de to siste $(p=0,047)$. Andelen korrekte oppsett sett i relasjon til sykehistorien økte fra $76 \%$ til $84 \%(p=0,029)$ i den samme perioden.

I alt ble 72 av 630 dødsfall bedømt som mulig unaturlige. Andelen var høyest i prosjektperioden (tab 4). Halvparten av de meldepliktige dødsfallene skyldtes beinbrudd/ frakturer, i hovedsak hos pasienter i høy alder (median alder 83 år). Rettslig likundersøkelse ble gjennomført ved ti (16\%) av de unaturlige dødsfallene i perioden mai-desember 2008. Opplysninger om hvorvidt det var gitt melding til politiet, skrev seg fra muntlige informasjon fra kliniker eller ble funnet i notater i journal eller epikrise. Sannsynligvis ble ikke alle meldinger notert $\mathrm{i}$ journalen, bare ved 32 av 62 meldepliktige dødsfall i perioden mai-desember er det holdepunkter for at slik melding er gitt.

Diskrepansen mellom patologenes og klinikernes oppfatning av meldeplikt skriver seg først og fremst fra dødsfall som følge av beinbrudd etter fallulykker hos multimorbide, eldre pasienter. Under studieperioden ble det likevel registrert en forbigående økning i antall meldinger til politiet etter henvendelse fra patolog til kliniker. Ingen av de patologavdekkede mulig unaturlige dødsfallene i mai ble meldt (0/7), i oktober var andelen økt til fire av seks. Andelen patologavdekkede meldinger sank imidlertid igjen til null i november og desember (hhv. $0 / 4 \operatorname{og} 0 / 3$ ). Til tross for årstiden var bare tre av de aktuelle dødsfallene relatert til brudd.

I henhold til journalene ble ingen meldinger om mulig dødelig legemiddelbivirkning sendt RELIS i mars 2007 eller i mars 2008 (tab 5). I prosjektperioden ble åtte av i alt 25 mistenkte legemiddelinduserte dødsfall meldt til RELIS. De fleste meldingene hadde sammenheng med antitrombotisk behandling eller legemiddelassosiert ulcus ventriculi. Det ble ikke meldt noen dødsfall som følge av antibiotikaassosiert kolitt.

\section{Diskusjon}

Selv om prinsippene bak oppsettet i dødsattesten bør være lett forståelige for leger med basal kunnskap om sykdommers opprinnelse og utvikling, viser det seg i praksis at oppsettene byr på store vanskeligheter. At en tredel av oppsettene ved vårt sykehus var ulogiske, kan forklares ut fra stadig mer kompliserte sykehistorier og flere parallelle sykdomsforløp som kan føre til døden hos multimorbide pasienter. Dessverre skyldtes mange ulogiske oppsett sannsynligvis også at utfyllerne har glemt lærdommen fra medisinstudiet og heller ikke har tatt seg tid til å lese skjemaets bakside før utfyllingen.

Feil i logisk oppsett av dødsattest kan likevel føre til registrering av korrekt dødsårsak hvis feilen er åpenbart ulogisk og den 


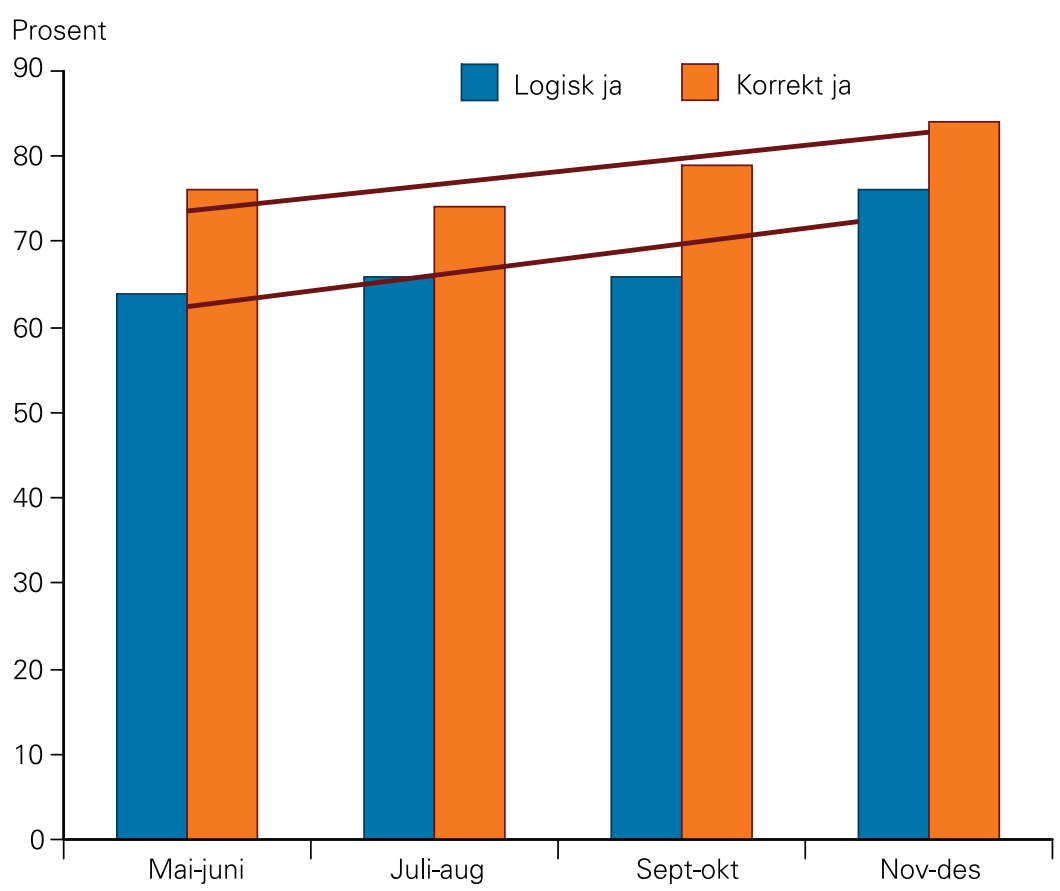

Figur 1 Andel dødsattester i prosjektperioden fra 1. mai til 31. desember 2008 med logisk oppsett, vurdert uavhengig av sykehistorie, eller korrekt oppsett, etter sammenlikning med sykehistorie. Trendlinjer er angitt, for logisk oppsett nederst ( $p=0,047)$, for korrekt oppsett øverst $(p=0,029)$

tilgrunnliggende dødsårsak er med i årsaksrekken. At viktige faktorer i sykehistorien er utelatt, kan derimot bare avgjøres gjennom å lese journalen. Etter gjennomgang av sykehistoriene fant vi vesentlige mangler ved
134 av 630 dødsattester (21\%), uavhengig av om årsaksrekken var logisk satt opp eller ikke.

Dødsårsaksstatistikkens pålitelighet er stadig gjenstand for debatt $(3,4)$. En måte å fange opp feil på er å la attestene gjennomgås av en tredje part for registrering. I Norge sendes dødsattestene via kommunelegen for slik gjennomgang før videresending til dødsårsaksregisteret. Rundt halvparten av de ulogiske attestene $i$ vår studie inneholdt de vesentligste kliniske funn og kunne la seg rekonstruere uten gjennomlesing av sykehistorien. Studier har vist at korrigering av åpenbart ulogiske attester ikke har vesentlig innvirkning på statistikken som helhet, noe som kan skyldes at andelen ulogiske dødsattester med relevante kliniske opplysninger er høy $(5,6) .15 \%$ av dødsattestene i prosjektperioden $i$ vår studie var imidlertid både ulogiske og ukorrekte og ville ha krevd gjennomgang av sykehistorien for korrigering.

Som alternativ til de klassiske undersøkelsene av attester med ulogiske oppsett sammenliknet Johansson \& Westerling sykdomskoder ved utskrivning med dødsattestdata for 1995 i Sverige og fant avvik ved halvparten av dødsfallene (7). En samkjøring av data fra dødsattester og utskrivningskoder viste at avvikene sannsynligvis ville ført til endring av tilgrunnliggende dødsårsak i $11 \%$ av tilfellene (8). En svakhet ved denne tilnærmingen er imidlertid at utskrivningskodene ved siste opphold ikke alltid gjenspeiler underliggende dødsårsak. Våre funn av manglende relevante kliniske opplysninger i $21 \%$ av dødsattestene kan tyde på at feilmarginene er større enn antatt ut fra registerbaserte undersøkelser.

Syning av døde og utfylling av dødsattest er i sykehus en oppgave som ofte overlates

Tabell 3 Eksempler på typer feil ved oppsett av dødsattester

\section{Dødsattest}

Eksempel 1

la. Sepsis

Ib. Kronisk lymfatisk leukemi

Eksempel 2

la. Hjertestans

lb. Hjerteklaffsykdom

og gammelt infarkt

Eksempel 3

la. Leversvikt

lb. Metastaser

II. Gastrointestinal stromal

tumor

Eksempel 4

la. Pneumoni

II. Kols

Eksempel 5

la. Lungebetennelse

II. Nyresvikt og hjertesvikt

\section{Eksempel 6}

la. Infeksjon/hjerteinfarkt

lb. Hjertesvikt/hypertoni

\section{Konklusjon}

Logisk ja, korrekt nei

Kommentar

Plateepitelkarsinom med spredning sannsynlig årsak til sepsis. Registrering av feil type malignitet i dødsårsaksregisteret

Logisk ja, korrekt nei

Ikke nevnt fallulykke med overarms fraktur og blødning. Ikke registrert som unaturlig dødsfall. Feil dødsårsak i dødsårsaksregisteret

Logisk nei, korrekt ja Alle elementer inkludert, sammenheng forståelig for dødsårsaksregisteret

Logisk nei, korrekt ja Alle elementer inkludert, sammenheng forståelig for dødsårsaksregisteret

Logisk nei, korrekt nei Grunnsykdom ikke angitt, immunsupprimert grunnet glomerulonefritt og idiopatisk trombocytopenisk purpura. Bare symptomer angitt under II. Feilregistrering som infeksjonssykdom i dødsårsaksregisteret sannsynlig

Logisk nei, korrekt nei Uten nærmere spesifisering ikke logisk at sykdommer nevnt i lb fører til infeksjon. Ikke nevnt mangeårig diabetes mellitus med nyresvikt og hypertoniutvikling. Sannsynlig feilregistrering som hjerteog karsykdom i dødsårsaksregisteret
Korrigert forslag

la. Sepsis

lb. Plateepitelkarsinom med metastaser sannsynlig utgangspunkt i lunge

II. Kronisk lymfatisk leukemi

la. Sannsynlig ferskt hjerteinfarkt

Ib. Blødning og sjokk

lc. Overarmsfraktur

II. Hjerteklaffsykdom

la. Leversvikt

lb. Metastaser

Ic. Gastrointestinal stromal tumor

la. Pneumoni

Ib. Kols

la. Lungebetennelse

lb. Immunsupresjon

lc. Glomerulonefritt

II. Idiopatisk trombocytopenisk purpura

la. Sepsis

lb. Nyresvikt med hypertensjon

lc. Diabetes mellitus 
til de minst erfarne legene på vakt. Vår studie kan tyde på at det er stort behov for tilbakemelding om dødsattestene. Utfyllende leger var uten unntak takknemlige for kommentarer og for at noen «brydde seg». At andelen korrekt utfylte dødsattester økte i studieperioden, tolkes som en direkte effekt av slik løpende tilbakemelding. Da antallet leger som skriver dødsattester i et sykehus på størrelse med vårt er høyt og utskiftningen stor, med nye turnusleger hvert halvår, vil opprettholdelse av kvalitetsøkningen kreve fortløpende tilbakemeldinger.

$\AA ̊$ avgjøre hva som er meldepliktig dødsfall, krever både erfaring og autoritet. Gjennomgangen av dødsfallene var spesielt nyttig for raskt å fange opp dødsfall der politiet burde kontaktes og for å løfte problemstillingen opp til avdelingsledelsen. Ikke uventet var melderutinene dårligst når det gjaldt dødsfall som følge av sykehusinfeksjoner og etter frakturer. Studier rundt manglende meldepraksis av frakturer fra England og Sverige har antydet at frakturer hos eldre pasienter ofte ikke anses som «ekte» ulykker og at det er en manglende forståelse for det overvåkende og forebyggende aspekt i loven $(9,10)$.

Unaturlig dødsfall og melding til politiet ble av flere leger ansett som ensbetydende med å antyde at dødsfallet kunne skyldes en kriminell handling. De gjentatte diskusjonene om behovet for melding også ved hofteleddsfrakturer etter snubling i fillerye på pleiehjemmet var ikke minst nyttige når det gjaldt å avdramatisere slike feiloppfatninger. Vi mener også at dette generelt har bidratt til å senke terskelen for å ta kontakt med politiet og dermed gjør det lettere å melde også andre typer unaturlig død i vårt sykehus.

Undersøkelse av legemidlers innvirkning på dødsårsaken krever ekspertise og betydelige ressurser. Tidligere studier fra sentralsykehuset i Akershus har vist at legemidler var medvirkende til $18 \%$ av dødsfallene ved medisinsk avdeling (11). I $8 \%$ var legemidler direkte årsak. Andelen mulig legemiddelassosierte dødsfall i vår studie var på $5 \%$ (34 av 630) og tilsvarte de direkte dødsfall som kunne avdekkes uten større ressursbruk eller farmakologisk ekspertise, så som for eksempel dødelig blødning ved antitrombotisk behandling. Tallene fra vår studie er derfor minimumstall.

\section{Konklusjon}

Med historisk lave obduksjonstall er vektlegging av kvalitetssikring ved død viktig. Kontinuerlig gjennomgang av dødsfallene, som skissert i vår studie, er ingen erstatning for obduksjon, men i et komplekst sykehusvesen bidrar det til å sikre at håndteringen av dødsfallene er enhetlig og i samsvar med lovpålagte rutiner.

Patologer er leger med spesiell kompetanse på dødsårsaksoppsett. Ved sykehus med patologiavdeling peker denne legegruppen

Tabell 4 Mulig unaturlige dødsfall

\begin{tabular}{lcccc} 
& $\begin{array}{c}\text { Mars 2007 } \\
\text { og mars 2008 }\end{array}$ & $\begin{array}{c}\text { Derav } \\
\text { rettslig }\end{array}$ & $\begin{array}{c}\text { Mai-desember } \\
2008\end{array}$ & $\begin{array}{c}\text { Derav } \\
\text { rettslig }\end{array}$ \\
\hline Kategori & Antall (\%) & Antall & Antall (\%) & Antall \\
\hline $\begin{array}{l}\text { Fraktur etter fall/ulykke } \\
\text { lalle typer) }\end{array}$ & 8 & 28 & 3 \\
\hline Postoperative dødsfall & 0 & 8 & 3 \\
\hline Sykehusinfeksjon' & 1 & 5 & 0 \\
\hline Yrkessykdom/skade & 0 & 3 & 0 \\
\hline Annet & 1 & 18 & 4 \\
\hline Meldeplikt, totalt antall & $10(7)$ & 0 & $62(12)$ & 10 \\
\hline 1'Infeksjoner etter frakturer ikke inkludert & & & &
\end{tabular}

Tabell 5 Mulig legemiddelinduserte dødsfall

\begin{tabular}{|c|c|c|c|c|}
\hline & $\begin{array}{l}\text { Mars } 2007 \\
\text { og mars } 2008\end{array}$ & $\begin{array}{l}\text { Meldt } \\
\text { RELIS }\end{array}$ & $\begin{array}{l}\text { Mai-desember } \\
2008\end{array}$ & $\begin{array}{l}\text { Meldt } \\
\text { RELIS }\end{array}$ \\
\hline Typer bivirkning & Antall (\%) & Antall & Antall (\%) & Antall \\
\hline $\begin{array}{l}\text { Blødning, alle typer antitrombotisk } \\
\text { behandling }\end{array}$ & 3 & 0 & 12 & 5 \\
\hline Antibiotikaassosiert kolitt & 4 & 0 & 4 & 0 \\
\hline $\begin{array}{l}\text { Ulcuser i øvre gastrointestinaltractus, } \\
\text { ikke-steroide antiflogistika eller } \\
\text { steroider }\end{array}$ & 0 & 0 & 4 & 2 \\
\hline Annet & 2 & 0 & 5 & 1 \\
\hline Totalt antall & $9(7)$ & 0 & $25(5)$ & 8 \\
\hline
\end{tabular}

seg derfor ut som egnet til å organisere slik løpende kvalitetssikring. Fra 1.1. 2009 ble kvalitetssikring av dødsattester og gjennomgang av sykehistorien med hensyn til ivaretakelse av lovpålagte melderutiner innført som fast rutine ved Akershus universitetssykehus. Rutinen medfører noe økt merarbeid enn i prosjektperioden, blant annet fordi dødsattester med vesentlige mangler nå blir korrigert. På sikt vil denne oppgaven derfor måtte bety økte ressurser til kvalitetssikringsarbeidet.

Oppgitte interessekonflikter: Ingen

Litteratur

1. FOR 2004-03-19 nr 542: Forskrift om obduksjon m.m. Lovdata. www.lovdata.no/for/sf/ho/ xo-20040319-0542.html (10.6.2009).

2. Dødsårsaker, 2007. Tabell 11. Dødsfall etter kjønn, alder og underliggende dødsårsak. Hele landet. Undergrupper. Oslo: Statistisk sentralbyrå, 2007. www.ssb.no/dodsarsak/tab-2009-04-07-11.html (10.6.2009).

3. Reseland S. Dødsårsaksregisteret har for dårlig kvalitet. Tidsskr Nor Legeforen 2009; 129: 894

4. Rogde S. Hvor pålitelig er dødsårsaksstatistikken? Tidsskr Nor Legeforen 2009: 129: 980.

5. Hoyert DL, Lima AR. Quering of death certificates in the United States. Public Health Rep 2005; 120: 288-93.

6. Lahti RA, Penttila A. Cause-of-death query in validation of death certification by expert panel. effects on mortality statistics in Finland, 1995. Forensic Sci Int 2003; 131: 113-24

7. Johansson LA, Westerling R. Comparing Swedish hospital discharge records with death certificates: implications for mortality statistics. Int J Epidemiol 2000; 29: 495-502.
8. Johansson LA, Westerling R. Comparing hospital discharge records with death certificates: can the differences be explained? J Epidemiol Community Health 2002: 56: $301-8$.

9. Calder SJ, Anderson GH, Gregg PJ. Certification of death in patients dying soon after proximal femoral fracture. BMJ 1996; 312: 1515.

10. Rammer L, Gustavsson E, Forsberg M et al. Brister $\mathrm{i}$ handläggingen av dödsfall utanför sjukhus. Läkartidningen 1997; 94: 4759-63.

11. Ebbesen J, Buajordet I, Erikssen J et al. Drugrelated deaths in a department of internal medicine. Arch Intern Med 2001; 161: 2317-23.

Manuskriptet ble mottatt 12.6. 2009 og godkjent 17.12. 2009. Medisinsk redaktør Trine B. Haugen. 